\title{
Componentes ricos em plaquetas na reparação de afecções tendo-ligamentosas e osteo- articulares em animais
}

\author{
Components rich in platelets used in wound healing tendon, ligaments and osteo-articular \\ diseases of animals
}

Leandro Maia' ${ }^{\mathrm{I}}$ Maria Verônica de Souza ${ }^{\mathrm{I}^{*}}$

\section{- REVISÃO BIBLIOGRÁFICA -}

RESUMO

O plasma rico em plaquetas e o concentrado de plaquetas são fontes de diversos fatores de crescimento, com grande potencial terapêutico. Uma vez liberados dos grânulos alfa das plaquetas ativadas, esses fatores atuarão no sítio da lesão, estimulando a quimiotaxia, fibroplasia e angiogênese, melhorando assim a reparação tecidual. Embora esses componentes ricos em plaquetas sejam de fácil obtenção e de eficácia comprovada na medicina humana e odontologia, a utilização desses componentes na medicina veterinária é relativamente recente, necessitando ainda de estudos controlados. Neste artigo, os aspectos morfológicos das plaquetas, a ação dos fatores de crescimento e a utilização de componentes ricos em plaquetas na reparação tecidual de estruturas tendo-ligamentosas e osteo-articulares são revisados.

Palavras-chave: plasma rico em plaquetas, concentrado de plaquetas, reparação tecidual, fatores de crescimento, tecido mole.

\section{ABSTRACT}

Platelet-rich plasma and platelet concentrates are involved in growing factors. Both have great therapeutic potential. When the alpha-granules are released by the active platelet, they act in the lesion site stimulating the chemotaxis, the fiberplasia and the angiogenesis. They improve the regeneration of the tissue. Although these rich platelet components are easy to obtain and efficiently to prove by medicine and dentistry, their use on vet medicine is recent. So, much more control studies need to be done. This article reviews morphological aspects of platelets, action of growing factors and use of components rich in platelet in wound healing tendons, ligaments and osteo-articular structures.
Key words: platelet-rich plasma, platelet concentrate, wound healing, growing factors, soft tissue.

\section{INTRODUÇÃO}

O plasma rico em plaquetas (PRP) e o concentrado de plaquetas $(\mathrm{CP})$ são fontes de fácil aquisição e de baixo custo de diversos fatores de crescimento, importantes na reparação tecidual devido às ações mitogênica, quimiotáxica e neovascular. De acordo com a literatura científica, após a ativação por agentes farmacológicos ou fisiológicos, as plaquetas presentes nesses componentes liberam diversos fatores de crescimentos presentes nos grânulos alfa ( $\alpha$-grânulos), que apresentam grande potencial terapêutico.

Na medicina humana e odontologia, o PRP/ CP já vem sendo utilizado há algum tempo, particularmente em procedimentos cirúrgicos para reparação óssea. Já na medicina veterinária o uso desses componentes é mais recente, sendo necessária a realização de estudos controlados nas diferentes espécies para validação e melhor aproveitamento da técnica. Nesse sentido, o objetivo deste trabalho é revisar os aspectos morfológicos das plaquetas, a ação dos fatores de crescimento e o potencial terapêutico desses fatores presentes em componentes ricos em

IDepartamento de Veterinária, Setor de Clínica, Universidade Federal de Viçosa (UFV), Campus Universitário, s/n, 36570-000, Viçosa, MG, Brasil. E-mail: msouza@ufv.br. *Autor para correspondência. 
plaquetas no tratamento de afecções tendoligamentosas e osteo-articulares de animais.

\section{DESENVOLVIMENTO}

Plaquetas e fatores de crescimento

$$
\text { As plaquetas são fragmentos }
$$

citoplasmáticos anucleados, discóides, derivados dos megacariócitos. São pequenas, possuindo cerca de 5 a $7 \mu \mathrm{m}$ de diâmetro e, normalmente, largura inferior a $3 \mu \mathrm{m}$. Ocasionalmente, nos eqüinos e cobaios, as plaquetas são lentiformes, podendo alcançar $20 \mu \mathrm{m}$ de diâmetro. Esses fragmentos apresentam importante função no processo de coagulação do sangue e são essenciais no processo inflamatório, na reparação tecidual através da interação célula-célula e liberação de mediadores solúveis provenientes da ativação destes. Nos ruminantes, a sobrevida é de aproximadamente 10 dias (FELDMAN et al., 2000).

Estruturalmente, as plaquetas apresentam microtúbulos, microfilamentos de actina e miosina, glicogênio, lisossomo, grânulos alfa ( $\alpha$-grânulos) e grânulos densos, localizados no citoplasma. Os grânulos densos contêm adenosina difosfato (ADP), adenosina trifosfato (ATP), serotonina e cálcio, enquanto os $\alpha$-grânulos possuem fatores de coagulação e de crescimento e outras proteínas (ZUCKER-FRANKLIN et al., 1988). Os á-grânulos são exemplos de organela secretora e apresentam compartimentalização e conteúdo protéico adquiridos por dois mecanismos distintos: biosíntese a partir dos megacariócitos e endocitose e pinocitose (HARRISON \& CRAMER, 1993).

Normalmente as plaquetas estão no estado inativo (EVERTS et al., 2006). A ativação das plaquetas pode ser realizada por agentes fisiológicos (ex: trombina, tromboxano, colágeno, ADP, fator ativador de plaquetas, serotonina e epinefrina) e farmacológicos (ex: o ionóforo de cálcio, o cloreto de cálcio e os análogos de endoperóxido cíclico) (BLOCKMANS et al., 1995; CARMONA et al., 2007). Acredita-se que todos esses agonistas desencadeiam seus efeitos por meio da interação com receptores localizados na membrana plasmática das plaquetas (BLOCKMANS et al., 1995). Após estimulação pelo agonista, os $\alpha$-grânulos plaquetários liberam proteínas por exocitose no local de lesão para iniciar o recrutamento de outras plaquetas, leucócitos e proteínas plasmáticas (HARRISON \& CRAMER, 1993).

Durante o preparo do PRP/CP, é importante o estudo prévio do agente ativador. Segundo SANCHEZ et al. (2003), a trombina bovina pode ocasionar o desenvolvimento de anticorpos contra os fatores de coagulação V, XI e a trombina, resultando em risco de vida decorrente de coagulopatias. De acordo com os autores, métodos seguros para o preparo do PRP incluem a utilização de trombina recombinante humana, trombina autóloga ou talvez extra-purificada. Estudo realizado em coelhos por SILVA (2007), com o propósito de se avaliar a ação do PRP em falhas ósseas realizadas no crânio de coelhos, demonstrou que a tromboplastina utilizada para a formação do gel de plaquetas incitou uma reação semelhante a do tipo corpo-estranho que atuou negativamente na fase inicial de reparação.

Uma vez ativadas, as plaquetas se modificam morfologicamente e desenvolvem pseudópodos, os quais promovem a agregação plaquetária e, posteriormente, a degranulação dos grânulos plaquetários (EVERTS et al., 2006). Em particular, os $\alpha$ grânulos das plaquetas são ricos em fatores de crescimentos com diversas ações biológicas. Entretanto, é importante ressaltar que a ativação das plaquetas deve ser realizada próximo ao momento da aplicação terapêutica, de forma a assegurar uma adequada concentração dos fatores de crescimento presentes nessas plaquetas (MAIA, 2008).

Os fatores de crescimento são peptídeos sinalizadores que regulam o metabolismo celular por meio da interação com um complexo de receptores de superfície celular, das vias de sinalização intracelular e, finalmente, do aumento da transcrição de fatores e produção de proteínas que resultam na proliferação e diferenciação celular, bem como no aumento da produção da matriz extracelular (DAHLGREN et al., 2001). Esses peptídeos liberados na matriz extracelular se ligam ao receptor tirosina-quinase, presente nas células teciduais. A ativação desse receptor resulta na sinalização de informações para genes responsáveis pelo controle da divisão celular, ocorrendo assim a transcrição do RNAm. Esse evento resulta em uma resposta biológica que inicia a cascata e que, por sua vez, ocasiona a reparação e a regeneração tecidual (ANTONIADES \& WILLIANS, 1983; SCHLIEPHAKE, 2002).

A degranulação plaquetária propicia a liberação das seguintes substâncias: fator de crescimento de transformação beta (TGF-ß), fibrinogênio, fator de crescimento derivado da plaqueta (PDGF), fator de crescimento epidermal (EGF), fator de crescimento de transformação alfa (TGF- $\alpha$ ), fator de crescimento vascular endotelial (VEGF), tromboplastina plaquetária, cálcio, serotonina e enzimas hidrolíticas (HARRISON \& CRAMER, 1993). Adicionalmente, outros fatores como o de crescimento fibroblástico (FGF) (EVERTS et al., 2006), o de crescimento de tecido 
conjuntivo (CTGF) (KUBOTA et al., 2004) e o semelhante à insulina I (IGF-I) (WEIBRIC et al., 2002) também estão presentes nas plaquetas.

Os fatores de crescimento podem ser classificados em dois grupos: morfométricos e mitogênicos. Os fatores de crescimento morfométricos estão envolvidos no crescimento ósseo por meio da transformação de células-tronco mesenquimais multipotentes em células osteoprogenitoras na presença da proteína óssea morfogênica (HOCK \& CANALIS, 1994). Já os fatores de crescimento mitogênicos estão relacionados ao aumento da população de células cicatriciais por mitogênese. De acordo com WERNER \& GROSE (2003), os fatores TGF$\beta$, EGF e IGF agem sinergicamente, melhorando o acesso das células inflamatórias para a área da lesão, assim como na angiogênese, fibroplasia e regeneração da pele (reepitelização). Resumidamente, os fatores de crescimento provenientes dos $\alpha$-grânulos plaquetários produzem quimiotaxia, proliferação e diferenciação celular, neovascularização e deposição da matriz extracelular (EVERTS et al., 2006). Detalhes sobre alguns deles são apresentados na tabela 1 .
Plasma rico em plaquetas e concentrado de plaquetas

O plasma rico em plaquetas é derivado do sangue total, contendo cinco vezes mais plaquetas (aproximadamente $1.000 .000 \mathrm{iL}^{-1}$ ) que os níveis fisiológicos (MARX et al., 1998). Esse componente pode ser obtido mediante uma (CAMARGO et al., 2002; PAGLIOSA \& ALVES, 2007) ou duas centrifugações (NUNES \& FILHO, 2007; PAGLIOSA \& ALVES, 2007; BARBOSA et al., 2008; MAIA, 2008) entre 200 e 2000g, durante três a cinco minutos. Já o concentrado de plaquetas é preparado a partir da centrifugação do PRP, sendo utilizada uma força gravitacional mais alta (entre 2000 e $6000 \mathrm{~g}$, durante dois minutos e meio e seis minutos), dependendo da força anteriormente utilizada para a obtenção do PRP (VENGELEN-TYLER, 1996).

$\mathrm{Na}$ medicina veterinária, a técnica para obtenção do PRP e CP vem sendo baseada na técnica utilizada para a espécie humana. O PRP/CP pode ser obtido por meio da coleta do sangue total em tubos ou bolsas de sangue contendo o anticoagulante citrato de sódio, após a centrifugação e ativação das plaquetas (CARTER et al., 2003; SUTTER et al., 2004; CARMONA, 2006; CARMONA et al., 2007; SCHNABEL et al., 2007;

Tabela 1 - Fonte e função de alguns fatores de crescimento presentes no plasma rico em plaquetas.

\begin{tabular}{|c|c|c|}
\hline Fator de crescimento & Fonte & Função \\
\hline $\begin{array}{l}\text { FC de transformação } \\
\text { beta (TGF- } ß)\end{array}$ & $\begin{array}{l}\text { Plaquetas, matriz óssea e cartilaginosa, } \\
\text { linfócitos T helper (Th1) ativados, célula } \\
\text { natural killer, macrófagos, monócitos e } \\
\text { neutrófilos. }\end{array}$ & $\begin{array}{l}\text { Estimula a proliferarão de células mesenquimais indiferenciadas; } \\
\text { regula a mitogênese endotelial, fibroblástica e osteoblástica; regula a } \\
\text { síntese de colágeno e secreção de colagenase; regula o efeito } \\
\text { mitogênico de outros fatores de crescimento; estimula a quimiotaxia } \\
\text { endotelial e angiogênese; inibe a proliferação de macrófagos e } \\
\text { linfócitos. }\end{array}$ \\
\hline $\begin{array}{l}\text { FC fibroblástico } \\
\text { básico (bFGF). }\end{array}$ & $\begin{array}{l}\text { Plaquetas, células mesenquimais, } \\
\text { macrófagos, condrócitos e osteoblastos. }\end{array}$ & $\begin{array}{l}\text { Promove o crescimento e diferenciação de condrócitos e osteoblastos; } \\
\text { é mitogênico para células mesenquimais; condrócitos e osteoblastos. }\end{array}$ \\
\hline $\begin{array}{l}\text { FC derivado da } \\
\text { plaqueta (PDGF). }\end{array}$ & $\begin{array}{l}\text { Plaquetas, osteoblastos, células } \\
\text { endoteliais, macrófagos, monócitos e } \\
\text { células musculares lisas. }\end{array}$ & $\begin{array}{l}\text { Mitogênico para células mesenquimais e osteoblastos; estimula a } \\
\text { quimiotaxia e mitogênese em fibroblastos, células da glia e } \\
\text { musculares lisas; regula a síntese de colágeno e secreção de } \\
\text { colagenase; estimula a quimotaxia de macrófagos e neutrofilos. }{ }_{1,6}\end{array}$ \\
\hline FC epidermal (EGF). & Plaquetas, macrófagos e monócitos. & $\begin{array}{l}\text { Estimula a quimiotaxia endotelial e angiogênese; regula a secreção de } \\
\text { colagenase; estimula a mitogênese epitelial e mesenquimal. }\end{array}$ \\
\hline $\begin{array}{l}\text { FC vascular } \\
\text { endotelial (VEGF). }\end{array}$ & Plaquetas e células endoteliais. & $\begin{array}{l}\text { Aumenta a angiogênese e permeabilidade vascular; estimula a } \\
\text { mitogênese de células endoteliais. }\end{array}$ \\
\hline $\begin{array}{l}\text { FC do tecido } \\
\text { conjuntivo (CTGF). }\end{array}$ & $\begin{array}{l}\text { Endocitose por plaquetas na medula } \\
\text { óssea. }\end{array}$ & $\begin{array}{l}\text { Promove angiogênese; regeneração da cartilagem; fibrose e adesão } \\
\text { plaquetária. } 11,12\end{array}$ \\
\hline $\begin{array}{l}\text { FC semelhante à } \\
\text { insulina I (IGF-I). }\end{array}$ & Plaquetas. & $\begin{array}{l}\text { Sinaliza as células mesenquimais e epiteliais a migrarem, dividirem e } \\
\text { aumentarem a síntese de colágeno e matriz. }{ }^{13}\end{array}$ \\
\hline
\end{tabular}

FC: fator de crescimento. 1: PIERCE et al. (1991), 2: BAMES et al. (1999), 3: MARSOLAIS \& FRENETTE (2005), 4: ROSIER et al. (1998), 5: WANG (1996), 6: FRIESEL \& MACIAG (1995), 7: CANALIS et al. (1989), 8: STEENFOS (1994), 9: MARTIN et al. (1992), 10: RHEE et al. (2004), 11: HOM \& MAISEL (1992), 12: KUBOTA et al. (2004),13: SCHWARTZ-ARAD et al. (2007). Fonte: Modificado a partir de EVERTS et al. (2006).

Ciência Rural, v.39, n.4, jul, 2009. 
ARGUELES et al., 2008; BARBOSA et al., 2008). O procedimento para a obtenção desses componentes ricos em plaquetas pode ser realizado utilizando-se centrífugas convencionais ou equipamentos que permitam a separação (aférese) dos constituintes do sangue total.

Em estudo que avaliou diferentes velocidades de centrifugação (1.300, 1.600 e 3.200rpm) do sangue total de cães para a obtenção do PRP, FERRAZ et al. (2006) constataram que a velocidade de centrifugação mais adequada após a primeira centrifugação de $800 \mathrm{rpm}$ por 10 minutos é de 1.600rpm pelo mesmo tempo. Esses autores obtiveram concentrações médias de 550.000 plaquetas $\mu 1^{-1}$ e ressaltam que as amostras submetidas a 3.200 rpm apresentaram alto grau de lise plaquetária, o que pode resultar em contagem aparente das plaquetas e falha da técnica devido à incapacidade desses fragmentos liberarem os fatores de crescimento.

ANITUA et al. (2004) ressaltaram que concentrações superiores a 300.000 plaquetas $\mu \mathrm{L}^{-1}$ são suficientes para o preparo do PRP. Já outros autores sugerem que o PRP deva ser preparado com concentrações de plaquetas de três a cinco vezes maiores que os níveis fisiológicos (GONSHOR, 2002; KEVY \& JACOBSON, 2004), os quais podem variar de acordo com a espécie (bovinos e ovinos: 800.000 a 1100.000 plaquetas $\mu \mathrm{L}^{-1}$; gatos: 300.000 a 800.000 plaquetas $\mathrm{iL}^{-1}$, caprinos: 300.000 a 600.000 plaquetas ì $\mathrm{L}^{-1}$; cães: 200.000 a 500.000 plaquetas $\mu \mathrm{L}^{-1}$ e eqüinos: de 100.000 a 350.000 plaquetas $\mu \mathrm{L}^{-1}$ (FELDMAN et al., 2000).

Diferenças na concentração de plaquetas no PRP entre diferentes espécies são relatadas (FERRAZ et al., 2006; MISHRA \& PAVELKO, 2006; ANDRADE et al., 2008; KAJIKAWA et al., 2008), o que dificulta a definição de um valor mínimo necessário para o seu preparo. Essas diferenças podem ser atribuídas à quantidade presente no sangue total, ao material de coleta (tubos ou bolsas de sangue), ao número de centrifugações realizadas e à velocidade de centrifugação, bem como a outras variáveis envolvidas na obtenção do PRP. Experimento realizado por MAIA (2008) a fim de tratar tendinite induzida experimentalmente no TFDS de eqüinos revelou a necessidade de adaptações nos protocolos disponíveis na literatura científica, para que se possam obter maiores concentrações de plaquetas no PRP a ser utilizado terapeuticamente. $\mathrm{O}$ autor realizou o descarte de parte do volume do plasma presente na superfície dos tubos após a primeira centrifugação, conseguindo assim concentrações plaquetárias variando de 320.000 a $500.000(407.500 \pm 58.800)$ plaquetas ì $\mathrm{L}^{-1}$ após a segunda centrifugação.
SCHNABEL et al. (2007), em estudo in vitro com fragmentos do tendão do músculo flexor digital superficial (TFDS) de eqüinos, demonstraram eficiência do PRP em concentração média de 395.000 plaquetas $\mu \mathrm{L}^{-1}$. Segundo BARBOSA et al. (2008), a concentração de plaquetas no PRP depende da contagem inicial no sangue total, ou seja, quanto maior o número inicial de plaquetas, mais rico será o PRP. Dessa forma, a presença de trombocitopenia é um fator limitante para a obtenção de concentração adequada de plaquetas.

O PRP atua na modulação e aceleração dos processos cicatriciais, sendo esses efeitos decorrentes dos fatores de crescimento contidos nos grânulos plaquetários (DINATO et al., 2001). A aplicação local de fatores de crescimento tem potencial terapêutico importante no tratamento de feridas crônicas, embora o exato mecanismo de ação sinérgica não esteja completamente elucidado (DEBUS et al., 2000). BENNETT \& SCHULTZ (1993) relataram que esses fatores aceleram a cicatrização de tecidos sadios e promovem a reparação de ferimentos. Segundo DECLAIR (1999), os fatores de crescimento são essenciais na regulação dos eventos celulares envolvidos no processo de cicatrização por propiciarem a quimiotaxia para o local da lesão e influenciarem significativamente a deposição da matriz extracelular.

Em humanos, o PRP tem sido associado a enxertos para reconstruções maxilo-faciais e tratamento de defeitos ósseos peridontais por estimular a regeneração óssea e a osteointegração, proporcionado assim a obtenção de um tecido ósseo de melhor qualidade (SILVA et al., 2006). Estudo recente realizado por MISHRA \& PAVELKO (2006) em 140 pacientes humanos com tendinite crônica demonstrou que o tratamento local com PRP reduz a dor, devendo ser uma opção terapêutica antes da intervenção cirúrgica.

ASPENBERG \& VIRCHENKO (2004) observaram que uma única administração intralesional de CP pode melhorar a reparação tendínea em ratos, sendo esse efeito decorrente dos fatores do crescimento liberados durante a ativação das plaquetas. Em pesquisa recente, KAJIKAWA et al. (2008) demonstraram, em ratos com lesão do tendão patelar, tratados com PRP, aumento $(\mathrm{P}<0,05)$ de células derivadas da circulação após três a sete dias depois de efetuada a lesão, quando comparados com o grupo controle. Esses resultados sugerem rápida ação do PRP nos primeiros dias após aplicação, demonstrando assim a necessidade de avaliação dessa terapia em diferentes fases do processo de cicatrização.

ISHIDA et al. (2007) estudaram a ação regenerativa do PRP in vitro e in vivo no menisco de coelhos. No estudo in vivo, os defeitos de $1,5 \mathrm{~mm}$ de 
diâmetro criados na região avascular do menisco foram tratados com PRP e gelatina de hidrogel $(\mathrm{GH})$ (grupo A), com plasma pobre em plaquetas e GH (grupo B) e apenas com GH (grupo C). A análise histopatológica realizada 12 semanas após o tratamento revelou melhora significativa no reparo do tecido dos animais do grupo A.

NAGAE et al. (2007), estudando o efeito do PRP em degeneração de disco intervertebral induzida em coelhos, evidenciaram, mediante estudo histológico e imunohistoquímico, que a associação do PRP com microesferas de gelatina de hidrogel $(\mathrm{MGH})$ promove supressão do processo degenerativo, além de intensa imunomarcação de proteoglicanos no núcleo pulposo e na camada interior do anel fibroso, em comparação com o uso isolado do PRP e do MGH tamponado (grupos de controle).

Em medicina veterinária, é crescente a utilização do PRP para realização de enxertos ósseos. Entretanto, PAGLIOSA \& ALVES (2007) ressaltam que, embora haja resultados contraditórios no uso do plasma rico em plaquetas como fonte de fatores de crescimento, há um evidente potencial de seu uso como estimulador na osteogênese em focos de fraturas, sendo necessária, no entanto, a padronização na obtenção e no emprego desse material como enxerto ósseo, já que a técnica de produção é relativamente simples e de baixo custo. SILVA et al. (2007), avaliando os efeitos do PRP autógeno em combinação com a hidroxiapatita nãoabsorvível na formação do calo ósseo em fraturas diafisárias induzidas em rádio de cães e fixadas com placas e parafusos ósseos, constataram que o PRP, em associação com a hidroxiapatita, não acelerou o processo de formação do calo ósseo, em comparação com a utilização isolada da hidroxiapatita (grupo controle). NUNES FILHO et al. (2007), em pesquisa recente, também não observaram benefícios do PRP quando utilizado isoladamente ou em combinação com o osso autógeno, com a finalidade de ocasionar reparação de cavidades ósseas no corpo da mandíbula de cães. Entretanto, BARBOSA et al. (2008), utilizando PRP associado ou não a auto-enxerto para reparação de falhas ósseas na crista da tíbia de cães, constatou que o uso combinado ao enxerto proporciona maior precocidade e uniformidade da radiopacidade nas falhas ósseas ao longo do tempo, em comparação com a utilização isolada do PRP e do enxerto.

AKEDA et al. (2006), estudando o disco intervertebral de suínos in vitro, constataram que o PRP foi efetivo na estimulação da proliferação celular, bem como no metabolismo da matriz extracelular, podendo assim ser aplicado por via local para estimular o reparo do disco intervertebral. MOOREN et al. (2007) compararam a eficácia do PRP associado ou não a enxerto autógeno em defeitos realizados na região frontal de caprinos $(\mathrm{N}=20)$. Os autores constataram em estudos histológicos e histomorfométricos que nas fases inicial e tardia da cicatrização óssea, a adição do PRP não promove melhoria do processo de reparação.

Em sete eqüinos acometidos de tendinite ou desmite, ARGUELLES et al. (2005) observaram, após tratamento com aplicação intralesional de PRP, redução na severidade da claudicação e melhora na imagem ultra-sonográfica das estruturas envolvidas. Alguns animais retornaram as suas atividades físicas após dois meses de tratamento. Em estudo recente realizado em cinco eqüinos, sendo dois acometidos com tendinite aguda do TFDS e três com desmite proximal do ligamento suspensório, ARGUELLES et al. (2008) observaram melhora clínica em ambas as afecções após tratamento intralesional com CP, porém a avaliação ultrasonográfica demonstrou que apenas os animais com tendinite apresentaram evolução positiva. Por outro lado, todos os eqüinos avaliados retornaram ao treinamento habitual seis meses após tratamento, não sendo observada recidiva até 20 meses após o mesmo, quando os animais ainda se encontravam sob observação.

Em estudo in vitro com fragmentos de TFDS de eqüinos, SCHNABEL et al. (2007) observaram que o PRP apresenta elevadas concentrações de fatores de crescimento, com efeitos anabólicos sobre a síntese da matriz tendínea quando comparado com outros produtos do sangue (plasma pobre em plaquetas, plasma total, sangue total e aspirado de medula óssea), além de aumentar a modulação na expressão de genes da matriz do tendão sem, entretanto, estimular simultaneamente o catabolismo de citocinas. CARMONA et al. (2007), utilizando CP no tratamento de osteoartrite nas articulações femorotibial, metacarpofalangiana, tarsocrural e talocalcâneocentralcalcâneoquartal de eqüinos, observaram melhora no grau de claudicação e redução na efusão articular. MAIA (2008) estudou experimentalmente a tendinite do TFDS de eqüinos $(\mathrm{N}=6)$ tratada com $\mathrm{PRP}$, sendo observada na histopatologia reparação tecidual uniforme e organizada 36 dias após aplicação intratendínea desse componente rico em plaquetas.

\section{CONCLUSÃO}

O plasma rico em plaquetas e o concentrado de plaquetas são alternativas para o tratamento de afecções em medicina veterinária. Entretanto, investigações científicas têm demonstrado resultados contraditórios dessas terapias em enfermidades osteoarticulares e tendo-ligamentosas. Portanto, mais 
estudos são necessários para determinar a eficácia dessas fontes de fatores de crescimento.

\section{AGRADECIMENTOS}

Os autores agradecem à Coordenação de Aperfeiçoamento de Pessoal de Nível Superior (CAPES), pela concessão da bolsa de mestrado ao pesquisador MAIA, e à Fundação de Amparo à Pesquisa do Estado de Minas Gerais (FAPEMIG), pelo apoio financeiro na execução de experimento com PRP para o tratamento de tendinite em eqüinos.

\section{REFERÊNCIAS}

AKEDA, K. et al. Platelet-rich plasma (PRP) stimulates the extracellular matrix metabolism of porcine nucleus pulposus and anulus fibrosus cells cultured in alginate beads. Spine, Philadelphia, v.31, n.9, p.959-966, 2006.

ANDRADE, M.G.S. et al. Evaluation of factors that can modify platelet-rich plasma properties. Oral Surgery, Oral Medicine, Oral Pathology, Oral Radiology, and Endodontology, St Louis, v.105, n.1, p.5-12, 2008.

ANITUA, E. et al. Autologous platelet source of proteins for healing and tissue regeneration. Thrombosis and Haemostasis, Aberdeen, v.91, n.1, p.4-15, 2004. Disponível em: http://www.schattauer.de/ in dex.php? id=1214\&doi=10.1160/T H 03 - 07 0440\&no_cache=1. Doi: 10.1160/TH03-07-0440.

ANTONIADES, H.N.; WILliAMS, L.T. Human plateletderived growth factor; structure and functions. Federation Proceedings, Bethesda, v.42, n.9, p.2630-2634, 1983.

ARGUELLES, D. et al. Clinical experiences with platelet-rich plasma as a treatment of tendon and ligament injuries in the horse. In: ANNUAL SCIENTIFIC MEETING, 16., 2005, Dublin, Ireland. Proceedings... Dublin: European College of Veterinary Surgeons, 2005. p.217-222. Capturado em 15 de dez. 2006. Online. Disponível em: http://www.equinesite.com/ articles $/$ modules.php? name $=$ News $\&$ file $=$ article $\&$ sid $=1178$

ARGUELLES, D. et al. Autologous platelet concentrates as a treatment for musculoskeletal lesions in five horses. Veterinary Record, London, v.162, n.7, p.208-211, 2008.

ASPENBERG, P.; VIRCHENKO, O. Platelet concentrate injection improves Achilles tendon repair in rats. Acta Orthopaedica Scandinavica, Lund, v.75, n.1, p.93-99, 2004. Disponível em: http://www.informaworld.com/smpp/ content $\sim \mathrm{db}=$ all content $=10.1080 / 00016470410001708190$. Doi: $10.1080 / 00016470410001708190$.

BAMES, G.L et al. Growth factor regulation of fracture repair. Journal of Bone and Mineral Research, Durhan, v.14, n.11, p.1805-1815, 1999.

BARBOSA, A.L.T. et al. Plasma rico em plaquetas: uma fonte de múltiplos fatores de crescimento para enxertos ósseos. Arquivo Brasileiro de Medicina Veterinária e Zootecnia, Belo Horizonte, v.58, supl.1, p.64-65, 2006.

BARBOSA, A.L.T. et al. Plasma rico em plaquetas para a reparação de falhas ósseas em cães. Ciência Rural, Santa
Maria, v.38, n.5, p.1335-1340, 2008. Disponível em: http:// www.scielo.br/scielo.php? script $=$ sci_arttext\&pid $=$ S0103$84782008000500021 \& \operatorname{lng}=$ pt\&nrm=iso\&tlng=pt. Doi: $10.1590 /$ S0103-84782008000500021.

BENNETT, N.T.; SCHULTZ, G.S. Growth factors and wound healing. Part II. Role in normal and chronic wound healing. American Journal of Surgery, Birmingham, v.166, n.1, p.74-81, 1993. Disponível em: http://www.sciencedirect.com/ science?_ob=ArticleURL\&_udi=B6VHS-4KSRYG3$\mathrm{S} \&$ _user $=687358 \&$ _rdoc $=1 \&$ fmt $=\&$ _orig $=$ search $\&$ _sort $=\mathrm{d} \& \mathrm{~V}$ iew $=$ c\&_acct $=$ C000037899\&_version $=1 \&$ _urlVersion $=0 \&$ us erid $=68 \overline{7} 358 \& \mathrm{md} 5=\mathrm{c} 55 \mathrm{e} 9 \mathrm{~d} 3 \overline{3} 2 \mathrm{~b} 839 \mathrm{bfa} 53 \overline{6} 589 \mathrm{f} 214 \mathrm{~b} 5 \mathrm{bbb} \bar{b} 6$. Doi: $10.1016 / \mathrm{S} 0002-9610(05) 80589-6$.

BLOCKMANS, D. et al. Platelet activation. Blood Reviews, Cambridge, v.9, n.3, p.143-156, 1995.

CAMARGO, P.M. et al. Platelet-rich plasma and bovine porous bone mineral combined with guided tissue regeneration in the treatment intrabony defects in humans. Journal of Periodontal Research, Los Angeles, v.37, n.4, p.300-306, 2002. Disponível em: http://www3.interscience.wiley.com/ journal/118943888/abstract?CRETRY=1\&SRETRY=0. Doi: 10.1034/j.1600-0765.2002.01001.x.

CANALIS, E et al. Effects of platelet-derived growth factor on bone formation in vitro. Journal of Cellular Physiology, Hoboken, v.140, n.3 p.530-537, 1989.

CARMONA, J.U. Use of autologous platelet concentrates for the treatment of muculoskeletal injuries in the horse. 2006. 91f. Tesis (Doctorado en Medicina y Sanidad Animales) - Universitat Autònoma de Barcelona.

CARMONA, J.U. et al. Autologous platelet concentrates as a treatment of horses with osteoarthiritis: a preliminary pilot clinical study. Journal of Equine Veterinary Science, Fort Collins, v.27, n.4, p.167-170, 2007.

CARTER, C.A. et al. Platelet-rich plasma gel promotes differentiation and regeneration during equine wound healing. Experimental and Molecular Pathology, Mississippi, v.74, n.3, p.244-255, 2003. Disponível em: http:// w w w. s c i e n c e d i r e c t. c o m / science?_ob=ArticleURL\&_udi=B6WFB-48CWY 8PC\&_user $=687358 \&$ \&doc $=1 \&$ \&mt $=\&$ \&_orig $=$ search $\&$ _sort $=\mathrm{d} \&$ view $=\mathrm{c} \&$ _acct $=\mathrm{C} 0000378$ 99\&_version $=1 \&$ \&urlVersi $\overline{\text { on }}=0 \&$ \&userid $=687358 \& \mathrm{md} 5=\mathrm{e} 6 \mathrm{f} 98 \mathrm{~d} 4 \mathrm{e} 65 \mathrm{e} 7 \mathrm{ebaab} 373 \mathrm{f} 624 \overline{\mathrm{d}} \mathrm{ee} 6 \mathrm{a} 6 \mathrm{e} 4$. Doi: 10.1016/S0014-4800(03)00017-0.

DAHLGREN, L.A. et al. Effects of ß-aminopropionitrile on equine tendon metabolism in vitro and on effects of insulinelike growth factor-Ion matrix production by equine tenocytes. American Journal Veterinary Research, Schaumburg, v.62, n.10, p.1557-1562, 2001.

DEBUS, E.S et al. The role of growth factors in wound healing. Zentralblatt für Chirurgie, Stuttgart, v.125, n.1, p.49-55, 2000 .

DECLAIR, V. The importance of growth factors in wound healing. Ostomy Wound Manage, Malvern, v.45, n.4, p.64$68,1999$.

Ciência Rural, v.39, n.4, jul, 2009. 
DINATO, C.J. et al. Plasma rico em plaquetas. In: DINATO C.J.; POLIDO D.W. Implantes osseointegrados: cirurgia e prótese. São Paulo: Artes Médicas, 2001. p.315-342.

EVERTS, P.A.M. et al. Platelet-rich plasma and platelet gel: a review. Journal of ExtraCorporeal Technology, Bloomsburg, v.38, n.2 p.174-187, 2006.

FELDMAN B.F. et al. Schalm's veterinary hematology. 5.ed. Philadelphia: Lippincott Williams \& Wilkins, 2000. 1344 p.

FERRAZ, V.C.M. et al. Concentração do plasma rico em plaquetas de cães obtida por três velocidades de centrifugação. Arquivo Brasileiro de Medicina Veterinária e Zootecnia, Belo Horizonte, v.58, supl.2, p.18, 2006.

FRIESEL, R.E.; MACIAG, T. Molecular mechanisms of angiogenesis: fibroblast growth factor signal transduction. Federation of American Societies for Experimental Biology, Bethesda, v.9, n.10, p.919-925, 1995.

GONSHOR, A. Technique for producing platelet-rich plasma e platelet concentrate: background and process. International Journal of Periodontics and Restorative Dentistry, Swampscott, v.22, n.6, p.547-557, 2002.

HARRISON, P., CRAMER, E.M. Platelet alpha-granules. Blood Review, Cambridge, v.7, n.1, p.52-62, 1993.

HOCK, J.M.; CANALIS, E. Platelet-derived growth factor enhances bone cell replication, but not differentiated function of osteoblasts. Endocrinology, Chevy Chase, v.134, n.3, p.1423-1428, 1994.

HOM, D.B.; MAISEL, R.H. Angiogenic growth factors: Their effects and potential in soft tissue wound healing. Annals of Otology Rhinology Laringology, Iowa, v.101, n.4, p.349354, 1992.

ISHIDA, K. et al. The regenerative effects of platelet-rich plasma on meniscal cells in vitro and its in vivo application with biodegradable gelatin hydrogel. Tissue Engineering, New York, v.13, n.5, p.1103-1112, 2007. Disponível em: http:/ /www.liebertonline.com/doi/abs/10.1089/ten.2006.0193. Doi: $10.1089 /$ ten. 2006.0193

KAJIKAWA, Y. et al. Platelet rich plasma initial mobilization circulation derived tendon healing. Journal of Cellular Physiology, Hoboken, v.215, n.3, p.837-845, 2008. Disponível em: http://www3.interscience.wiley.com/journal/117880365/ abstract. Doi: $10.1002 /$ jcp. 21368 .

KEVY, S.V.; JACOBSON, M.S. Comparison of methods for point of care preparation of autologous platelet gel. Journal of ExtraCorporeal Technology, Bloomsburg, v.36, n.1, p.28$35,2004$.

KUBOTA, S. et al. Abundant retention and release of connective tissue growth factor (CTGF/CCN2) by platelets. Journal of Biochemistry, Bethesda, v.136, n.3, p.279-282, 2004.

MAIA L. Plasma rico em plaquetas no tratamento de tendinite em eqüinos: avaliação clínica, ultra- sonográfica e histopatológica. 2008. 78f. Dissertação (Mestrado em Medicina Veterinária) - Curso de Pós-graduação em Medicina Veterinária, Universidade Federal de Viçosa.

MARSOLAIS, D.; FRENETT, J. Inflammation and tendon healing. Médecine Sciences, Paris, v.21, n.2, p.180-186, 2005 .

MARTIN, P. et al. Growth factors and cutaneous wound repair. Progress in Growth Factor Research, New York, v.4, n.1, p.25-44, 1992 .

MARX, R.E. et al. Platelet-rich plasma: growth factor enhancement for bone grafts. Oral Surgery, Oral Medicine, Oral Pathology, Oral Radiology, and Endodontology, St Louis, v.85, n.6, p.638-646, 1998. Disponível em: http:// w w w. $\mathrm{s}$ c i e $\mathrm{n}$ c e d i $\mathrm{r}$ e $\mathrm{c}$ t. science?_ob=ArticleURL\&_udi=B6WP1-4CP6W 38 $24 \&$ _user $=687358 \&$ _rdoc $=1 \&$ fmt $=$ \&_orig $=$ search $\&$ _s

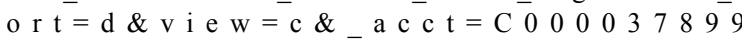
\& $\quad \mathrm{v}$ e r s i o n $=1 \&$ u r 1 V e r s i o $n=$ 0\&_userid $=687358 \& \mathrm{md} 5=$ eaaa $14 \mathrm{~b} 73872 \mathrm{fa} 77 \mathrm{~b} 02816338 \mathrm{e} 292 \mathrm{f} 79$. Doi: 10.1016/S1079-2104(98)90029-4.

MISHRA, A.; PAVELKO, T. Treatment of chronic elbow tendinosis with buffered platelet-rich plasma. American Journal of Sports Medicine, Chicago, v.34, n.11, p.17741778, 2006. Disponível em: http://ajs.sagepub.com/cgi/content/ abstract/34/11/1774. Doi: 10.1177/0363546506288850.

MOOREN, R.E. et al. The effect of platelet-rich plasma on early and late bone healing: an experimental study in goats. International Journal of Oral Maxillofacial Surgery, Guildford, v.36, n.7, p.626-631, 2007. Disponível em: http://

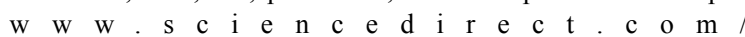
science? ob=ArticleURL\& udi=B6WGW-4NSV159$2 \&$ \& us e r $=687358 \&$ r d o c $=1 \& \quad$ fm t $=\& \quad$ orig

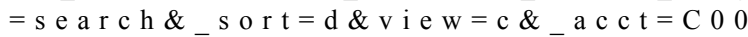

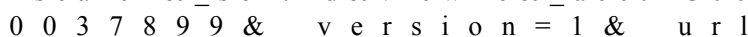
Version $=0 \&$ userid $=687358 \& \mathrm{md} 5=7 \mathrm{fb} 4389$ adeea4830b22117a17606dffd. Doi: $10.1016 /$ j.ijom.2007.03.013

NAGAE, M. Intervertebral disc regeneration using plateletrich plasma and biodegradable gelatin hydrogel microspheres. Tissue Engineering, New York, v.13, n.111, p.147-158, 2007. Disponível em: http://www.liebertonline.com/doi/abs/10.1089/ ten.2006.0042. Doi: 10.1089/ten.2006.0042.

NUNES FILHO, D.P. Avaliação microscópica da ação do osso autógeno associado ou não ao PRP em cavidades ósseas de cães. Revista Implantnews, São Paulo, v.4. n.3, p263-269, 2007.

PAGLIOSA, G.M.; ALVES, G.E.S. Considerações sobre a obtenção e o uso do plasma rico em plaquetas e das células mesenquimais indiferenciadas em enxertos ósseos. Ciência Rural, Santa Maria, v.37, n.4, p.1202-1205, 2007. Disponível em: http://www.scielo.br/ s c i e lo.php ? s cript $=$ sci_art text \& pid $=$ S $0103-$ $84782007000400050 \& \operatorname{lng}=$ en $\& n r m=$ iso\&tlng=pt. Doi: $10.1590 /$ S0103-84782007000400050.

PIERCE G.F. et al. Role of platelets-derived growth factoring wound healing. Journal of Cellular Biochemistry, Hoboken, v.45, n.4, p.319-326, 1991. 
RHEE, J.S et al. The functional role of blood platelet components in angiogenesis. Trombosis Haemostasis, Aberdeen, v.92, n.2, p.394-402, 2004.

ROSIER, R.N et al. The potential role of transforming growth factor beta in fracture healing. Clinical Orthopaedics Related Research, Philadelphia, sup1.355, p.294-300, 1998.

SANCHEZ, A.R. et al. Is platelet-rich plasma the perfect enhancement factor? A current review. International Journal of Oral \& Maxillofacial Implants, Guildford, v.18, n.1, p.93$103,2003$.

SCHNABEL, V.L et al. Platelet Rich Plasma (PRP) enhanced anabolic gene expression patterns in flexor digitorum superficialis tendons. Journal of Orthopaedic Research, Hoboken, v.25, n.2, p.230-240, 2007.

SCHLIEPHAKE, H. Bone growth factors in maxillofacial skeletal reconstruction. International Journal of Oral and Maxillofacial Surgery, Guildford, v.31, n.5, p.469-484, 2002.

SCHWARTZ-ARAD, D. et al. The use of platelet rich plasma (PRP) and platelet rich fibrin (PRF) extracts in dental implantology and oral surgery. Refuat Hapeh Vehashinayim, Tel Aviv, v.24, n.1, p.51-55, 2007.

SILVA, P.S.A. Plasma rico em plaquetas (PRP) associado ou não ao osso esponjoso autógeno no reparo de falhas ósseas experimentais. 2007. 32f. Dissertação (Mestrado em Medicina Veterinária) - Curso de Pós-graduação em Medicina Veterinária, Universidade Federal de Viçosa.

SILVA, S.B. et al. Plasma rico em plaquetas e hidroxiapatita em rádio de cães. Arquivo Brasileiro de Medicina Veterinária e Zootecnia, Belo Horizonte, v.58, supl.2, p.56, 2006.

SILVA, S.B et al. Plasma rico em plaquetas combinado a hidroxiapatita na formação do calo ósseo em fraturas induzidas experimentalmente no rádio de cães. Ciência Rural, Santa Maria, v.37, n.4, p.1045-1051, 2007. Disponível em: http://www.scielo.br/ s c i e lo.php? s cript $=$ s ci arttext\&pid $=$ S $0103-$ $84782007000400020 \& \operatorname{lng}=\mathrm{en} \& n \overline{r m}=$ iso\&tlng=pt. Doi: $10.1590 /$ S0103-84782007000400020.

STEENFOS, H.H. Growth factors and wound healing. Scandinavian Journal of Plastic and Reconstructive Surgery and Hand Surgery, Göteborg, v.28, n.2, p.95-105, 1994.

SUTTER, W.W. et al. Comparison of hematologic values and transforming growth factor-beta and insulin-like growth factor concentrations in platelet concentrates obtained by use of buffy coat and apheresis methods from equine blood. American Journal Veterinary Research, Schaumburg, v.65, n.7, p.924930, 2004. Disponível em: http://avmajournals.avma.org/doi/ abs/10.2460/ajvr.2004.65.924. Doi: 10.2460/ajvr.2004.65.924.

VENGELEN-TYLER, V. Technical manual. 12.ed. Bethesda, MD: American Association of Blood Banks, 1996. 752 p.

WANG, J.S. Basic fibroblastic growth factor for stimulation of bone formation in osteoinductive or conductive implants. Acta Orthopaedica Scandinavica, Göteborg, suppl.269, p.1-33, 1996.

WEIBRIC, G. et al. Quantification of thrombocyte growth factors in platelet concentrates produced by discontinuous cell separation. Factor Growth, London, v.20, n.2, p.93-97, 2002.

WERNER, S.; GROSE, R. Regulation of wound healing by growth factors and cytokines. Physiological Reviews, Houston, v.83, n.3, p.835-870, 2003. Disponível em: http://physrev.physiology.org/ cgi/content/full/83/3/835. Doi: 10.1152/physrev.00031.2002.

ZUCKER-FRANKLIN, D. et al. Atlas of blood cells: function and pathology. 2.ed. Philadelphia: Lea \& Febiger, 1988. $777 \mathrm{p}$. 